\title{
An effective route for the micropropagation of Medinilla formosana through ovary culture in vitro
}

\author{
Y. Wang, D.D. Feng, X.B. Li, J.P. Chen
}

Wang Y., Feng D.D., Li X.B., Chen J.P., 2015. An effective route for the micropropagation of Medinilla formosana through ovary culture in vitro. Ann. For. Res. 58(2): 235-243.

Abstract. Medinilla formosana Hayata, a beautiful endangered shrub of the family Melastomataceae endemic in Taiwan of China, is recalcitrant for micropropagation in vitro until now. And tissue browning after cutting generally occurred in the tissue culture of Medinilla species was considered to be the greatest obstacle. To avoid the serious cut-browning, immature ovaries in $0.3 \mathrm{~cm}$ diameter of $M$. formosana were taken as initial explants in this study, and its aseptic plantlets were obtained for the first time. The highest survival level (12.7 plantlets per ovary) after 3 months of culture were observed on 1/2 MS supplemented with $0.5 \mathrm{~g}$ $1^{-1}$ active carbon and $0.4 \mathrm{~g} \mathrm{l}^{-1}$ casein hydrolysate ( $\left.\mathrm{pH} 5.5\right)$. Furthermore, $\beta$-mercaptoethanol proved to be an effective inhibitor for its browning response of $M$. formosana in vitro. And $1 / 2 \mathrm{MS}$ media supplemented with $6.67 \mu \mathrm{M}$ BA, $0.11 \mu \mathrm{M}$ NAA, $0.5 \mathrm{mM} \beta$-Met and $0.2 \mathrm{~g} \mathrm{l}^{-1}$ AC proved appropriate for its multiplication. Finally rooted plantlets were transplanted into the greenhouse after acclimatization, and the micropropagation system of $M$. formosana was successfully established. This report first details an efficient method for the in vitro micropropagation of Medinilla plants. Keywords Medinilla, ovary culture, browning, inhibitor, micropropagation.

Authors. Yan Wang, Dai-Di Feng, Jian-Ping Chen (jpchen2001@126.com) State Key Laboratory Breeding Base for Zhejiang Sustainable Pest and Disease Control, Ministry of Agriculture Key Laboratory of Biotechnology in Plant Protection, Institute of Virology and Biotechnology, Zhejiang Academy of Agricultural Sciences, Hangzhou 310021, China; Xiao-Bai Li - Institute of Horticulture, Zhejiang Academy of Agricultural Sciences, Hangzhou 310021, China.

Manuscript received May 18, 2015; revised June 18, 2015; accepted June 29, 2015; online first June 29, 2015.

\section{Introduction}

Medinilla formosana Hayata is an endangered shrub native from Taiwan, China (Boufford et al. 2003, Zhang 2013). It has great ornamental value due to its evergreen leaves, attractive panicles and long-lasting fruits, and is used indoors as well as in gardens $(\mathrm{Wu}$ et 
al. 1994, Chyuan 2006). However, traditional propagation by seeds and cuttings are slow and laborious, resulting in insufficient quantity and high prices in horticulture market. Meanwhile, excessive acquisition of propagating materials might greatly damage the forest ecosystem of origin area.

Although in vitro techniques have been recommended for plant reproduction and germplasm conservation, there are few reports focused on the micropropagation of Medinilla species. However, most of Medinilla have great horticultural decorative value, such as M. crassata, M. magnifica and M. scortechinii. Only in 1970s and ' 80 s, the culture of M. magnifica in vitro was attempted to initiate from the epidermal tissues (Than Than Van et al. 1978), root and shoot tips (Reinert et al. 1977, Debergh and Maene 1981), but no viable meristem cultures have been obtained so far. Casteele et al. (1981) suggested that was partly attributed to the serious browning response of the tissues, which was caused by the rapid oxidation reactions of the abundant tannins and highly active polyphenol oxidase in the plant after cutting. Similarly in our preliminary experiments, the leaf and shoot explants of $M$. formosana were also found severely affected by browning once placed in culture, hence elimination/reduction of browning damage is crucial for the success of Medinilla species tissue culture. Additionally, shoot tips and stem nodes of Medinilla are usually setose and coarse, which brings great disinfection difficulty to their culture in vitro. Therefore in this study, the underdeveloped glabrous ovaries of $M$. formosana were chosen as the initial culture materials to reduce contamination and avoid the ensuing browning response. Firstly, anatomical observation was undertaken to identify the characteristics of ovule development, and then ovary at the appropriate stage were cultured to obtain viable plantlets, using media containing a range of plant growth supplements. Browning inhibitors were then tested on the cultures of aseptic cut shoots. Finally, optimal media for the mul- tiplication and rooting of $M$. formosana were screened to establish its micropropagation system. This study will assist work to establish culture of $M$. formosana originating from other explants tissue, and also lay the foundation for the large-scale micropropagation of Medinilla species.

\section{Material and methods}

\section{Anatomical observation of ovule develop- ment}

The source plants $M$. formosana Hayata were grown in the greenhouse of the Zhejiang Academy of Agricultural Sciences, Hangzhou City. To avoid contamination with exogenous pollen, self-crossing was performed by bagging before the blossom on sunny mornings in July 2013. Pollinated ovaries of M. formosana, which were from $0.1 \mathrm{~cm}$ to $0.4 \mathrm{~cm}$ diameter, were fixed for 1 day in FAA solution (a mixture of $70 \%$ ethanol, $40 \%$ formalin and glacial acetic acid, 90: 5: 5, v/v/v), dehydrated by using an graded ethanol series $(70,80,95,100 \%$, $\mathrm{v} / \mathrm{v}$ ), hyalinized in dimethylbenzene, and embedded in paraffin. The embedded ovaries were longitudinally sectioned $(10 \mu \mathrm{m})$ and stained in Heidenhain's hematoxylin solution $(0.5 \%$, w/v). Finally, slides sealed with neutral balsam were observed through light microscope (Olympus SP 350, Japan) and photographed (Wang et al. 2011). There were three replicates for each stage sample.

\section{Protocol establishment of ovary culture}

According to the histological study above, ovaries of M. formosana before abortion were collected for further culture. They were surfacesterilized in $75 \%(\mathrm{v} / \mathrm{v})$ ethanol for $1 \mathrm{~min}$ first, and then soaked in $1 \%(\mathrm{w} / \mathrm{v})$ sodium hypochlorite solution (available chlorine concentration) for $8 \mathrm{~min}$ and $0.1 \%(\mathrm{v} / \mathrm{v})$ mercuric chloride for $6 \mathrm{~min}$, finally rinsed four times with sterile wa- 
ter. Ovaries were then cut into quarters and inoculated, keeping the incision contacted with the medium. 1/2 MS (Murashige and Skoog, 1962) supplemented with $3 \%(\mathrm{w} / \mathrm{v})$ sucrose and $0.7 \sim 0.8 \%(\mathrm{w} / \mathrm{v})$ agar was taken as the basal medium. And four kinds of media with different combinations of additives and $\mathrm{pH}$ were tested in order to maximize the survival level (Table 1). To provide the uniform hardness, agar dosage of each medium was fine adjusted according to the $\mathrm{pH}$ design. After an initial 2 weeks' dark-culture, the explants were transferred under fluorescent light $\left(40 \mu \mathrm{mol} \mathrm{m} \mathrm{m}^{-2} \mathrm{~s}^{-1}\right)$ with a $16 \mathrm{~h}$ photoperiod; the room temperature was always kept at $25 \pm 2{ }^{\circ} \mathrm{C}$. When the ovules were matured and germinated, seedlings were carefully transferred onto $1 / 2 \mathrm{MS}$ medium containing $0.2 \mathrm{~g} \mathrm{l}^{-1}$ active carbon (AC) and $0.89 \mu \mathrm{M}$ 6-benzyladenine (6-BA) for further growth. The number of viable seedling germinated from one ovary was counted to evaluate survival levels. There were ten replicates for each medium, and four quarter-ovary explants were inoculated in each Petri dish.

\section{Screening of browning inhibitors for culture in vitro}

Five kinds of browning inhibitors, including $\mathrm{AC}$, ascorbic acid (ASA), polyvinylpyrrolidone (PVP), $\beta$-mercaptoethanol ( $\beta$-Met), and glutathione (GSH) were added to the basic $1 / 2 \mathrm{MS}$ media (3\% sucrose, $0.8 \%$ agar, and $\mathrm{pH}$ 5.5 ) at different gradient concentrations (Bhat and Chandel 1991; Madhusudhanan and Rahiman 2000). Radicles of $M$. formosana seed- lings were excised and shoots with 4-6 leaves were transferred onto these media, and then cultured at $25 \pm 2{ }^{\circ} \mathrm{C}$ with a $16 \mathrm{~h}$ photoperiod under $60 \mu \mathrm{mol} \mathrm{m}{ }^{-2} \mathrm{~s}^{-1}$ fluorescent light. After 1 week's culture, leaf color of M. formosana after inoculation was observed to evaluate the effectiveness of the browning inhibitors. Shoots (before and after cutting) cultured on basic medium were taken as controls, and there were four shoots for each bottle and five replicate bottles for each medium.

\section{Multiplication and rooting culture}

After selecting the most effective browning inhibitor, multiplication and rooting of $M$. formosana was tested. Shoots with 5 6 leaves were excised (2-3 cm long) and inoculated vertically on six types of proliferation medium to multiply through cluster buds (Table 2, Medium A-F). After 8 weeks, the shoot number was counted to calculate and compare their multiplication ratios. After that, clustering shoots were excised and transferred to rooting medium for root induction (Table 2, Medium G-I), and numbers of roots was recorded 2 weeks later. Finally, rooted plantlets were transplanted into greenhouse after acclimatization. In all cases, the basal medium was $1 / 2$ MS supplemented with 3\% sucrose, $0.8 \%$ agar and $\beta$-Met, $\mathrm{pH}$ 5.5. Cultures were maintained at $25 \pm 2{ }^{\circ} \mathrm{C}$ with a $16 \mathrm{~h}$ photoperiod under 60 $\mu \mathrm{mol} \mathrm{m} \mathrm{m}^{-1} \mathrm{~s}^{-1}$ fluorescent light. There were four shoots for each bottle and five replicate bottles for each medium.

Table 1 Survival levels of ovules on different media

\begin{tabular}{lllllcc}
\hline Medium & \multicolumn{2}{c}{ Composition $\left(\mathrm{g} \mathrm{l}^{-1}\right)$} & $\mathrm{pH}$ & $\begin{array}{l}\text { No. of } \\
\text { explants }\end{array}$ & $\begin{array}{l}\text { No. of } \\
\text { seedlings }\end{array}$ & $\begin{array}{l}\text { survival levels } \\
\text { (/ovary) }\end{array}$ \\
\cline { 2 - 7 } & $\mathrm{AC}^{\#}$ & $\mathrm{CH}$ & 5.5 & 40 & 0 & $0 \pm 0 \mathrm{~d}$ \\
$\mathrm{~A}$ & 0.0 & 0.4 & 5.5 & 40 & 38 & $3.8 \pm 1.64^{\mathrm{c}}$ \\
$\mathrm{B}$ & 0.5 & 0.0 & 5.5 & 40 & 127 & $12.7 \pm 2.59^{\mathrm{a}}$ \\
$\mathrm{C}$ & 0.5 & 0.4 & 5.8 & 40 & 94 & $9.4 \pm 1.67^{\mathrm{b}}$ \\
$\mathrm{D}$ & 0.5 & 0.4 & &
\end{tabular}

Note. Abbreviations: $\mathrm{AC}^{\#}$ - active carbon, $\mathrm{CH}$ - casein hydrolysate. The results are the means of ten replicates. For a medium, Means \pm standard error within a column followed by the same letter are not significantly different according least significant difference (LSD) at $p \leq 0.05$. 
Table 2 Multiplication and rooting of $M$. formosana on different media

\begin{tabular}{|c|c|c|c|c|c|c|c|}
\hline \multirow[b]{2}{*}{ Medium } & \multicolumn{3}{|c|}{ Composition } & \multirow[b]{2}{*}{$\begin{array}{l}\mathrm{AC} \\
\left(\mathrm{g} \mathrm{l}^{-1}\right)\end{array}$} & \multirow{2}{*}{$\begin{array}{l}\text { Initial shoots for } \\
\text { propagation/ } \\
\text { rooting }\end{array}$} & \multirow[b]{2}{*}{$\begin{array}{l}\text { No. of multiplied } \\
\text { buds / roots }\end{array}$} & \multirow{2}{*}{$\begin{array}{l}\text { Multiplication } \\
\text { ratios/average } \\
\text { root number }\end{array}$} \\
\hline & $\begin{array}{l}6-\mathrm{BA} \\
(\mu \mathrm{M})\end{array}$ & $\begin{array}{l}\text { NAA } \\
(\mu \mathrm{M})\end{array}$ & $\begin{array}{l}\beta \text {-Met } \\
(\mathrm{mM})\end{array}$ & & & & \\
\hline $\bar{A}$ & 0.44 & 0.05 & 0.25 & 0.0 & 20 & 33 & $1.65 \pm 0.44^{\mathrm{d}}$ \\
\hline B & 2.22 & 0.05 & 0.25 & 0.0 & 20 & 57 & $2.85 \pm 0.41^{\mathrm{c}}$ \\
\hline $\mathrm{C}$ & 4.44 & 0.11 & 0.25 & 0.0 & 20 & 96 & $4.80 \pm 0.58^{b}$ \\
\hline $\mathrm{D}$ & 6.67 & 0.11 & 0.25 & 0.0 & 20 & 142 & $7.10 \pm 0.77^{\mathrm{a}}$ \\
\hline $\mathrm{E}$ & 4.44 & 0.11 & 0.50 & 0.2 & 20 & 53 & $2.65 \pm 0.66^{\mathrm{c}}$ \\
\hline $\mathrm{F}$ & 6.67 & 0.11 & 0.50 & 0.2 & 20 & 82 & $4.10 \pm 0.70^{\mathrm{b}}$ \\
\hline$\overline{\mathrm{G}}$ & 0.00 & 0.54 & 0.50 & 0.0 & 20 & 32 & $1.60 \pm 0.28^{\mathrm{b}}$ \\
\hline $\mathrm{H}$ & 0.00 & 0.54 & 0.50 & 0.2 & 20 & 101 & $5.05 \pm 0.41^{\mathrm{a}}$ \\
\hline I & 0.00 & 1.07 & 0.50 & 0.2 & 20 & 105 & $5.55 \pm 0.55^{\mathrm{a}}$ \\
\hline
\end{tabular}

Note. The results are the means of five replicates. Means \pm standard error within a column followed by the same letter are not significantly different according LSD at $p \leq 0.05$. Media A-F for multiplication and G-I for rooting were analyzed separately.

\section{Statistical analysis}

The treatments were arranged in a completely randomized design. The data collected were analyzed for ANOVA using SPSS 17.0 software package (SPSS Inc., Chicago, USA).

\section{Results}

\section{Development characteristics of ovules}

Ovarian anatomical observation of $M$. formosa$n a$ was performed to identify its developmental characteristics. Figure 1 showed their embryo sac was of polygonum-type as reported by Watson and Dallwitz (1992), and developed normally after pollination when the ovary was $0.1 \mathrm{~cm}$ in diameter. Zygotes successfully developed into a globular-shaped embryo when the ovary was $0.2 \mathrm{~cm}$ in diameter; however ovules with only a few free endosperm nuclei could be observed, followed by the multicellular endosperm later which did not fill the whole embryo sac till the heart-shaped stage (Fig.1 B-C). When the ovary reached $0.4 \mathrm{~cm}$ diameter, most embryos began to abort (Fig. 1D), but there were still a small number of embryos could develop further to the cotyledon-shaped stage (Fig. 1E).

\section{Establishment of in vitro cultures from ovaries}

Since the $0.3 \mathrm{~cm}$-diameter ovary was indicated still healthy and therefore the ovary culture was conducted at this stage. Quarter-sectioned ovaries were inoculated on media listed in Table 1 and cultured under condition mentioned in Materials and methods section. All explants turned from the original pink color to brown, sometimes very dark, within a few days (Fig. 2A). After about 3 months' incubation, ovules developed to mature seeds and then germinated on three media except medium A (Table 1, Fig. 2 B). Medium $\mathrm{C}$ gave the highest survival level of 12.7 plantlets per ovary and significantly higher than other media (Table 1).

\section{Screening of browning inhibitors for tissue culture}

In our study, the shoot leaves of M. formosana began to turn copper-red color (as shown in Fig. 2E) after 1 week of root-cutting. To overcome this browning response in vitro, effects of several inhibitors were studied, taken the leaf color as a browning indicator. The diagram (Fig. 3) showed that $1.0 \mathrm{~g} \mathrm{l}^{-1} \mathrm{AC}$ had a weak depression on the color change and no significant effect was observed on other inhibi- 


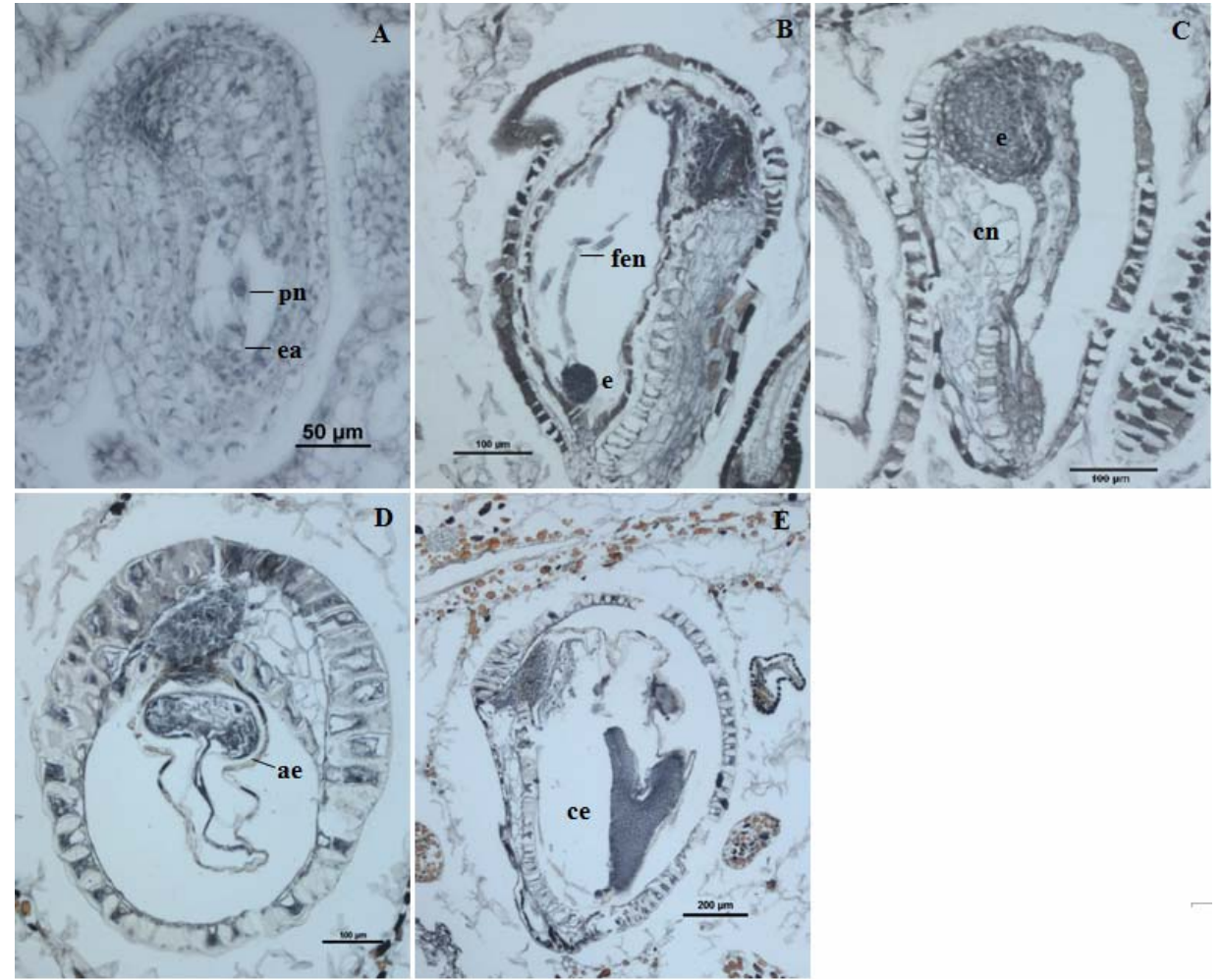

Figure 1 Stained sections through ovules of $M$. formosana

(A) The normal polygonum-type embryo sac in a $0.1 \mathrm{~cm}$ diameter ovary; (B) globular-shaped embryo formed in a $0.2 \mathrm{~cm}$ diameter ovary; (C) the abnormal ovule in a $0.3 \mathrm{~cm}$ diameter ovary; (D) aborted embryo in a $0.4 \mathrm{~cm}$ diameter ovary, scale bar $=100 \mu \mathrm{m}$; (E) normal cotyledon-shaped embryo in a $0.4 \mathrm{~cm}$ diameter ovary, scale bar $=200 \mu \mathrm{m}$. pn, polar nucleus; ea, egg apparatus; e, embryo; fen, free endosperm nuclei; cn, cellular endosperm; ae, aborted embryo; ce, cotyledonary embryo

tors. Nevertheless, all leaves kept green color when the concentration of $\beta$-Met was over 0.25 $\mathrm{mM}$, and its action concentration should be increased to $0.5 \mathrm{mM}$ when combined to $0.2 \mathrm{~g} \mathrm{l}^{-1}$ AC. However, the red leaves of most plantlets cultured on control and other media recovered green color finally after several months' culture.

\section{Establishment of micropropagation system for M. formosana}

The micropropagation of $M$. formosana became possible once the browning response was found effectively controlled by $\beta$-Met. Five media for proliferation and three media for rooting were tested. As the results shown in Table 2, the multiplication ratio increased with increasing concentration of 6-BA and NAA. However, the shoots cultured on media A-D were emaciated and slightly hyperhydrated in appearance. But the supplementary AC improved their growth (media $\mathrm{E}$ and $\mathrm{F}$ ), and medium $F$ gave the suitable multiplication rate (4.10) for the large-scale production.

After 1 week for rooting, short white roots could be induced from the stem base of $M$. formosana in media $\mathrm{H}$ and $\mathrm{I}$, while the rooting on medium G was observed after about 2 weeks' culture. As shown in Fig. 2 F, red aerial roots were strongly induced from the stem nodes of plantlets in media $\mathrm{G}$, and the root number was 

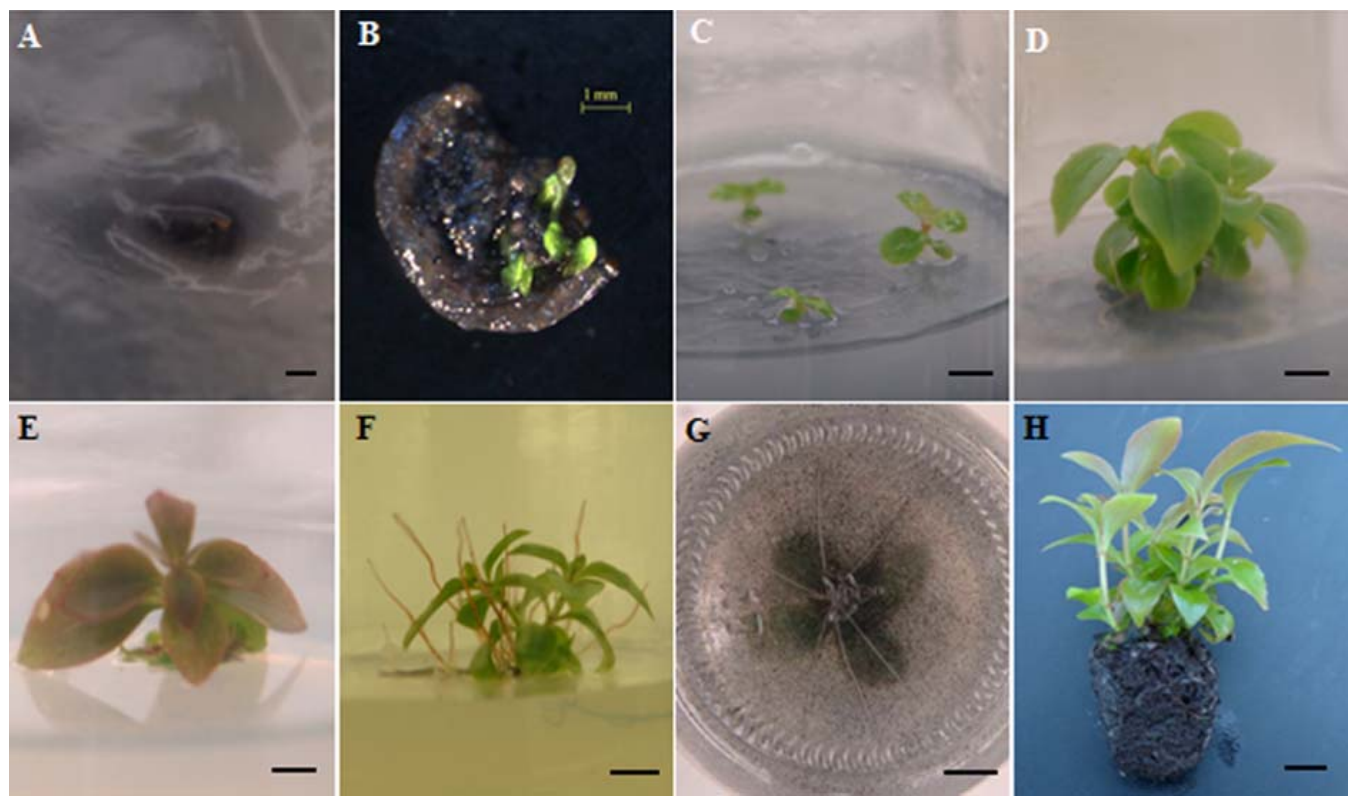

Figure 2 Ovary culture and micropropagation of M. formosana

(A) The immature ovary explant showed severe browning after inoculation, and matured and germinated (B), scale bar = $1 \mathrm{~mm}$; (C) Little seedlings released from the maternal tissue, and (D) viable plantlets were obtained, but (E) they turned severe brown after root-cutting, scale bar $=5 \mathrm{~mm}$; (F) Aerial roots were easily induced on the medium without $\mathrm{AC}$, and $(\mathrm{G})$ only normal roots were induced on media with $\mathrm{AC}$, and then rooted plantlet $(\mathrm{H})$ were transplanted into substrate, scale $b a r=1 \mathrm{~cm}$.

significantly less than those of $\mathrm{H}$ and I (Table 2 ). And there was no significant difference about the root status between medium $\mathrm{H}$ and $\mathrm{I}$. Finally, all shoots for root induction were rooted and the plantlets were acclimatized, potted in substrate, and then successfully transferred to the greenhouse for continued development (Fig. $2 \mathrm{G}, \mathrm{H}$ ).

\section{Discussion}

It has been reported the endosperm can provide nutriment substance for the developing young embryo as a highly nutritive tissue in most angiosperms, and hence it usually develops earlier than embryo (Wardlaw 1955, Wang et al. 2011). However in our study, histological observation displayed the multicellular endosperm of $M$. formosana degraded prematurely (Fig.1), which was very likely to result in malnutrition and eventual abortion of embryo. And the success of ovary culture also suggested that there is a direct relationship between embryo abortion and nutrient availability. AC appears to be crucial for the culture of M. formosana, probably owing to its absorbability for toxic substances secreted from cutting site. In addition, ovary survival is better on a medium with relatively acid $\mathrm{pH}$, which was suggested more suitable for the growth of tropical plants (Rao et al. 1997).

Generally, the browning process was thought to be a consequence of the oxidation of phenolic compounds catalyzed by polyphenol oxidase, caused the formation of toxic quinines and melanin, which are deleterious and adverse to plant tissues (Walker \& Ferrar, 1998, Sarni-Manchado et al. 2000, Tang \& Newton, 2004, Yingsanga et al. 2008, Xu et al. 2011). 


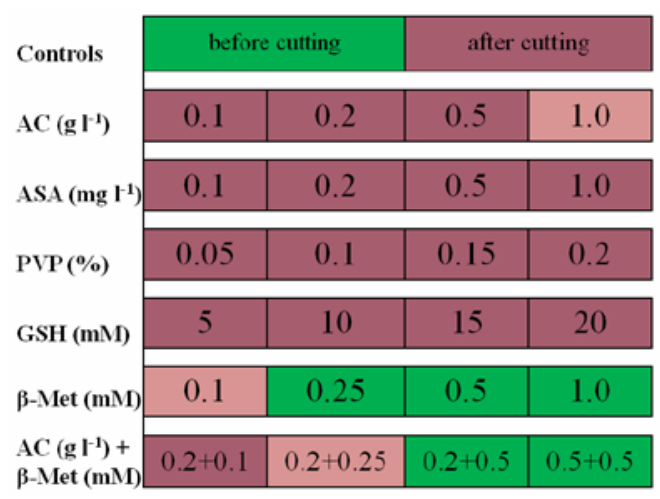

Figure 3 Leaf color diagram of $M$. formosana cultured on media with different browning inhibitors

Green represented the leaf color of normal plantlet, copper-red stood for the leaf color of severe brown shoot, and reddish color represented the leaf color of slight brown shoot. AC - active carbon, ASA - ascorbic acid, PVP - polyvinylpyrrolidone, GSH - Glutathione, $\beta$ Met - $\beta$-mercaptoethanol.

In our study, $\beta$-Met proved a strong browning inhibitor, and it might contribute to its remarkable reducibility which could depress the enzymatic oxidation reaction of phenols. As shown in Fig 3, 2.5mM was the action concentration of $\beta$-Met, but the addition of AC raised its dose thresholds due to the absorption probably. Although Casteele et al. (1981) had previously found $\beta$-Met could depress the activity of hydrolysable tannin polyphenol oxidase on the chemical level, it is used in the tissue culture of Medinilla species for the first time. Noteworthily, leaf color recovered normal green after long-term culture, which suggested that the browning response might be an adaptive reaction of plant to wound or other unfavorable surroundings and its toxicity folded up when the plant gradually adapted the growth circumstance. Dörnenburg and Knorr (1997) also suggested plant browning occurred when a physical stress sufficient to cause membrane damage, and the release of phenylalanine ammonialyase and the high peroxidase could help resist the stress. Therefore, the death of M. magnifica occurred in the previous studies might be largely attributed to injury from the disinfectants used or bacterial erosion rather than browning (Debergh \& Maene 1981). Hence further study is needed to gain a better understanding of plant adaptive mechanism after cutting during tissue culture.

$\mathrm{AC}$ is seems indispensable for both multiplication and rooting culture of $M$. formosana in our study, as also reported in the tissue culture of Salix, mesquite tree, banana, etc. (Liesebach \& Naujoks 2004, Soniya \& Sujitha 2006, Buendia-Gonzalez et al. 2007, Xiao et al. 2007, Joshi \& Dhawan 2007, Agarwal \& Kanwar 2007, Thomas 2008). Besides, the growth of aerial roots was found to be avoided by the use of AC in our study (Fig. 2), and the similar phenomenon was reported by Werckmeister (1971). It is quite likely associated with the lights arrangement in most culture rooms that several culture-flats are overlapped on a single shelf. Negatively geotropic aerial roots of some plants might be induced by the interference light on the bottom of culture containers from the lower flats. However, the addition of AC could effectively darken the media and create a favorable environment for root development.

\section{Conclusions}

In this study, we reported that the immature $0.3 \mathrm{~cm}$-diameter ovaries of $M$. formosana precultured for 2 weeks on 1/2 MS medium supplemented with $\mathrm{CH}$ and $\mathrm{AC}(\mathrm{pH} 5.5)$ in dark, then cultured under light for 90 days, could produce plantlets with survival rates of 12.7 per ovary $(P \leq 0.05)$; and $\beta$-Met proved to be effective for browning inhibition in tissue culture, making the in vitro micropropagation of M. formosana come true. To our knowledge, this research is the first report for the micropropagation of Medinilla species via the use of ovary culture, which provides the basis for the in vitro culture originating from other explants and the future large-scale production of Medinilla plants. 


\section{Acknowledgements}

This work was jointly supported by grants from National Natural Science Foundation of China (NSFC) (No.31301800) and the Introduction of International Advanced Agricultural Science and Technology Plan, Chinese Ministry of Agriculture (Program 948, No.2011-G31).

\section{References}

Agarwal S., Kanwar K., 2007. Comparison of genetic transformation in Morus alba L. via different regeneration systems. Plant Cell Reports 26: 177-185. DOI: 10.1007/s00299-006-0217-3.

Bhat S.R., Chandel K.P.S., 1991. A novel technique to overcome browning in tissue culture. Plant Cell Reports 10: 358-361. DOI: 10.1007/BF00193159.

Boufford D. E., Ohashi H., Huang T. C., Hsieh C. F., Tsai J. L., Yang K. C., Peng C. I., Kuoh C. S., Hsiao A., 2003. A checklist of the vascular plants of Taiwan. Flora of Taiwan 6: 15-139.

Buendia-Gonzalez L., Orozco-Villafuerte J., Cruz-Sosa F., Chavez-Avila V.M., Vernon-Carter E.J., 2007. Clonal propagation of mesquite tree (Prosopis laevigata Humb. \& Bonpl. ex Willd. M.C. Johnston). I. via cotyledonary nodes. In Vitro Cellular \& Developmental Biology Plant 43: 260-266. DOI: 10.1007/s11627-007-9027-8.

Casteele K. L. V., Dauw-van Keymeulen M. I., Debergh P. C., Maene L. J., Flamée M. C., Van Sumere C. F., 1981. The phenolics and a hydrolysable tannin polyphenol oxidase of Medinilla magnifica. Phytochemistry, 20(5):1105-1112. DOI: 10.1016/0031-9422(81)830361.

Chyuan J.H., 2006. Improvement of cutting propagative of Medinilla formosana Hayata and M. macnifica. Bulletin of the Hualien District Agricultural Improvement Station, 19: 28.

Debergh P.C., Maene L.J., 1981. A scheme for commercial propagation of ornamental plants by tissue culture. Scientia Horticulturae 14(4): 335-345. DOI: 10.1016/03044238(81)90047-9.

Dörnenburg H., Knorr D., 1997. Evaluation of elicitor-and high-pressure-induced enzymatic browning utilizing potato (Solanum tuberosum) suspension cultures as a model system for plant tissues. Journal of Agricultural and Food Chemistry 45(10): 4173-4177. DOI: 10.1021/ jf9701603.

Joshi P., Dhawan V., 2007. Assessment of genetic fidelity of micropropagated Swertia chirayita plantlets by ISSR marker assay. Plant Biology 51: 22-26. DOI: 10.1007/ s10535-007-0005-0.

Liesebach M., Naujoks G., 2004. Approaches on vegetative propagation of difficult-to-root Salix caprea. Plant
Cell, Tissue and Organ Culture 79: 239-247. DOI: 10.1007/s11240-004-0665-9.

Madhusudhanan K., Rahiman B.A., 2000. The effect of activated charcoal supplemented media to browning of in vitro cultures of Piper species. Biologia Plantarum 43(2): 297-299. DOI: 10.1023/A:1002729032527.

Murashige T., Skoog F., 1962. A revised medium for rapid growth and bioassays with tobacco tissue cultures. Physiologia Plantarum 15: 473-497. DOI: 10.1111/ j.1399-3054.1962.tb08052.x.

Rao I.M., Borrero V., Ricaurte J., Garcia R., Ayarza M.A., 1997. Adaptive attributes of tropical forage species to acid soils. III. Differences in phosphorus acquisition and utilization as influenced by varying phosphorus supply and soil type. Journal of Plant Nutrition 20(1): 155-180. DOI: 10.1080/01904169709365240.

Reinert J., Bajaj Y.P.S., 1977. Applied and fundamental aspects of plant cell, tissue and organ culture. Springer, Berlin. DOI: 10.1007/978-3-662-02279-5.

Sarni-Manchado P., Le Roux E., Le Guernevé C., Lozano Y., Cheynier V., 2000. Phenolic composition of litchi fruit pericarp. Journal of Agricultural and Food Chemistry 48: 5995-6002. DOI: 10.1021/ jf000815r.

Soniya E.V., Sujitha M., 2006. An efficient in vitro propagation of Aristolochia indica. Biologia Plantarum 50: 272-274. DOI: 10.1007/s10535-006-0018-0.

Tang W., Newton R.J., 2004. Increase of polyphenol oxidase and decrease of polyamines correlate with tissue browning in Virginia pine (Pinus virginiana Mill.). Plant Science 167(3): 621-628. DOI: 10.1016/ j.plantsci.2004.05.024.

Than Than Van K., Trinh H., 1978. In frontiers of plant tissue culture. Calgary, Alta, Canada.

Thomas T.D., 2008. The role of activated charcoal in plant tissue culture. Biotechnology Advances 26(6): 618-631. DOI: 10.1016/j.biotechadv.2008.08.003.

Wang Y., Cheng Q., Zhu X.Y., Chen L.P., 2011. Studies on reproductive characteristics of an interspecific chimera between Brassica juncea and Brassica oleracea. Plant Cell, Tissue and Organ Culture 104: 209-215. DOI: 10.1007/s11240-010-9822-5.

Walker J.R. L., Ferrar P.H., 1998. Diphenol oxidases, enzyme-catalysed browning and plant disease resistance. Biotechnology and Genetic Engineering Reviews, 15(1): 457-498. DOI: 10.1080/02648725.1998.10647 966.

Wardlaw C.W., 1955. Embryogenesis in plants. Methuen, Ltd., London. DOI: 10.5962/bhl. title.5655.

Watson L., Dallwitz M.J., 1992. The families of flowering plants: descriptions, illustrations, identification, and information retrieval. Version: $10^{\text {th }}$ October 2013. Web: http://delta-intkey.com.

Werckmeister P., 1971. Light induction of geotropism, and the control of proliferation and growth of Cymbidium in tissue culture. Botanical Gazette 132(4): 346-350. DOI: 10.1086/ 336601.

Wu Z.Y., Peter H.R., Hong D.Y., 1994. Flora of China. Science Press (Beijing) \& Missouri Botanical Garden 
(St. Louis) 13: 393-394.

Xiao W., Huang X.L., Huang X., Chen Y.P., Dai X.M., Zhao J.T., 2007. Plant regeneration from protoplasts of Musa acuminate cv. Mas (AA) via somatic embryogenesis. Plant Cell, Tissue and Organ Culture 90:191-200. DOI: 10.1007/s11240-007-9241-4.

Xu Y.W., Zeng J.W., Zou Y.T., Husaini A.M., Yao R.Y., Wu D.G., 2011. Combined effect of dark and wounding on regeneration potential of Houttuynia cordata Thunb. leaves. Indian Journal of Experimental Biology 49: 540-546.
Yingsanga P., Srilaong V., Kanlayanarat S., Noichinda S., McGlasson W. B., 2008. Relationship between browning and related enzymes (PAL, PPO and POD) in rambutan fruit (Nephelium lappaceum Linn.) cvs. Rongrien and See-Chompoo. Postharvest biology and technology, 50(2):164-168. DOI: 10.1016/j.postharvbio.2008. 05.004 .

Zhang S.Z., 2013 Vegetation ecology of the Midst of Tajen Experimental Forest Station, Taitung County.[master's thesis.] Pingtung, National Pingtung University of Science and Technology, pp.12-18. 